\title{
Studying Gene Expression in Irradiated Barley Cultivars: PM19L-like and CML31-like Expression as Possible Determinants of Radiation Hormesis Effect
}

\author{
Irina V. Gorbatova ${ }^{1,+}{ }^{\text {, Elizaveta A. Kazakova }}{ }^{1,+}{ }^{+}$, Mikhail S. Podlutskii ${ }^{1}$, Ivan A. Pishenin ${ }^{1}$, \\ Vladimir S. Bondarenko ${ }^{1}$, Aleksandra A. Dontsova ${ }^{2}$, Dmitriy P. Dontsov ${ }^{2}$, \\ Aleksei S. Snegirev ${ }^{1}{ }^{(D}$, Ekaterina S. Makarenko $\left.{ }^{1}{ }^{(}\right)$, Sofia V. Bitarishvili ${ }^{1}$, \\ Maria A. Lychenkova ${ }^{1}$, Taras V. Chizh ${ }^{1}$ and Polina Yu. Volkova ${ }^{1, * \mathbb{D}}$ \\ 1 Laboratory of Molecular and Cellular Radiobiology, Russian Institute of Radiology and Agroecology, \\ Kievskoe shosse, 109 km, 249032 Obninsk, Russia; gorbatova.irina.96@mail.ru (I.V.G.); \\ elisabethafeb19@gmail.com (E.A.K.); mikhail.podlutskii@gmail.com (M.S.P.); \\ pishenin.Ivan@gmail.com (I.A.P.); Bvs79@mail.ru (V.S.B.); snegir.05@mail.ru (A.S.S.); \\ makarenko_ek_obninsk@mail.ru (E.S.M.); bitarishvili.s@gmail.com (S.V.B.); \\ lychenkovamariya@gmail.com (M.A.L.); taras.chizh@rambler.ru (T.V.C.) \\ 2 Laboratory of Selection and Seed Winter Barley, Agricultural Research Center "Donskoy", Nauchny Gorodok, \\ 3, 347740 Zernograd, Russia; doncova601@mail.ru (A.A.D.); dontsova601@gmail.com (D.P.D.) \\ * Correspondence: volkova.obninsk@gmail.com \\ + These authors contributed equally to this work.
}

Received: 23 October 2020; Accepted: 19 November 2020; Published: 22 November 2020

check for updates

\begin{abstract}
Gamma $(\gamma)$-irradiation of plants at low doses can provoke a broad range of growthstimulating effects. In order to reveal universal target genes that are involved in molecular pathways of radiation hormesis establishment, we studied nine barley cultivars for their tolerance to $\gamma$-irradiation of seeds. Four morphological traits were assessed in barley seedlings after $\gamma$-irradiation of seeds at $20 \mathrm{~Gy}$. Nine cultivars were sorted according to the sensitivity to irradiation as $\gamma$-stimulated, "no morphological effect", or $\gamma$-inhibited. Gene expression of 17 candidate genes was evaluated for the 7 most contrasting cultivars. Changes in expression of barley homologues of PM19L and CML31 were suggested as possible determinants of radiation hormesis effect. The possible role of jasmonate signaling in roots in radiation growth stimulations was revealed. Morphological analysis and gene expression study showed that the genetic background of a cultivar plays an important role in eustress responses to low-dose $\gamma$-irradiation of seeds.
\end{abstract}

Keywords: Hordeum vulgare; $\gamma$-irradiation; low doses; eustress; growth stimulation; PM19L; CML31

\section{Introduction}

Low concentrations and intensities of various stressors can induce stimulating effects on growth and development of plants [1]. The beneficial effect of low intensities of stress exposure on plants is often determined as "positive stress" or eustress, while the effects of harmful high doses of stressors are called distress [2]. $\gamma$-irradiation at low doses causes a wide range of positive effects on plant growth (radiation hormesis effect), including an increase in linear size of organs and accumulation of biomass and certain metabolites [3-6]. Considering that hormetic eustress responses are widespread in control and environmental conditions [1,7], their molecular basis can be unspecific and can depend on activation and suppression of similar pathways under the impact of stressors with different modes of action. 
Due to the instability of the radiation hormesis effect in field conditions, its expediency as a ubiquitous agricultural practice is questionable. However, exposing plants at stimulating doses of $\gamma$-irradiation is a promising approach for obtaining knowledge about candidate genes for growth improvement, which can find application in the biotechnology of agricultural crops. In a changing environment, hormesis-based interventions in agriculture and food systems are expected to ultimately enhance the resilience of agriculture [7].

The potential of a given radiation dose to elicit eustress or distress responses depends on many factors, including the plant species, cultivar, stage of development, radiation quality, as well as many others [8]. The mechanistic understanding of hormesis manifestation after irradiation of seeds is especially important. The transition from seed dormancy to germination is the key event in plant life. During and after germination, early seedling growth is supported by the catabolism of reserved protein, oil, or starch stores accumulated during seed maturation. These reserves support cell growth, chloroplast development, and root growth until photoauxotrophic growth conditions [9]. As a rule, seed $\gamma$-irradiation in the dose range of 5-20 Gy accelerates growth and development of plants while doses between 20 and 100 Gy are considered inhibitory [4]. After irradiation of seeds at low doses, moderate damage allows mobilization of endosperm resources, even under limited growth conditions [6].

In a series of experiments on the spring barley cultivar Nur, we demonstrated that irradiation of barley seeds in the dose range of 15-20 Gy induced growth stimulation in seedlings [10], transcriptional changes in embryos several hours after seed irradiation and forward developmental shift of irradiated plants [5], as well as metabolomic rearrangements, including nitrogen redistribution between shoots and roots [6]. These experiments were conducted using the first reproduction of the Nur cultivar after certified seeds, and findings of those studies require confirmation on a certified genetically homogenous seeds of different cultivars, considering high variability of the stimulating effect depending on the year of harvest and reproduction of a cultivar [5]. Therefore, to elucidate the molecular pathways that are involved in stimulation effect of low-dose irradiation, we used a range of barley cultivars different in their growth response to seed $\gamma$-irradiation and studied the expression of candidate genes revealed after transcriptomic analysis of embryos of irradiated barley seeds [5].

\section{Materials and Methods}

\subsection{Barley Cultivars, Seed Irradiation, and Growth Conditions}

The original seeds of nine Hordeum vulgare L. cultivars, namely, Vivat, Grees, Eryoma, Leon, Master, Ratnik, Timofey, Fedos, and Fox 1, were used for morphological screening. Cultivars have morphologically distant traits and different yield (Supplementary Table S1), suggesting sufficient genetic diversity for the goals of the study performed. These cultivars are recommended for use in the climate conditions of South Russia, Armenia, and Ukraine and have distant origins (Supplementary Table S1). The certified seeds were provided by the Agrarian Science Center "Donskoy" (Zernograd, Russia) and belonged to the harvest of 2018. Seeds were irradiated using $\gamma$-facility "GUR-120" $\left({ }^{60} \mathrm{Co}\right)$ at the Russian Institute of Radiology and Agroecology (Obninsk, Russia). Seeds were placed in plastic envelops (approximately 1000 seeds per envelope) and irradiated at the dose of $20 \mathrm{~Gy}$ (dose rate $60 \mathrm{~Gy} / \mathrm{h} \mathrm{[10]).} \mathrm{The} \mathrm{relative} \mathrm{humidity} \mathrm{of} \mathrm{seeds} \mathrm{was} 16-18 \%$, and the treatment was performed at room temperature $\left(20-2{ }^{\circ} \mathrm{C}\right)$. Non-irradiated seeds of each cultivar were used as a control.

Immediately after treatment, irradiated and control seeds were planted on soaked in distilled water paper rolls (Supplementary Figure S1). Each paper roll contained approximately 100 seeds; 16 paper rolls per cultivar were used (8 paper rolls for irradiated and 8 paper rolls for control seeds). The paper rolls were placed for incubation in MIR-254 (Sanyo, Moriguchi, Japan), under $20{ }^{\circ} \mathrm{C}$ in the dark in order to maintain homogenous conditions for all paper rolls and to simulate early stages of development in field conditions, where access of germinated seed to light is restricted. In total, 
morphological parameters of approximately 15,000 seedlings were assessed in the experiment (primary data are shown in Supplementary Table S2).

\subsection{Morphological Assessment of Seedlings}

Shoot and root lengths were measured after 7 days of germination using a ruler. Shoot and root biomasses were measured using analytical balance PA213C (Ohaus, New York City, NY, USA) and recalculated for 100 plants. These data were used to rank the cultivars based on morphological response to seed $\gamma$-irradiation.

\subsection{Cultivars Ranking}

For each morphological trait (root length, shoot length, root biomass of 100 plants, and shoot biomass of 100 plants), the ratio of mean values for irradiated and control plants of each cultivar was calculated. For the ratio exceeding $100 \%$, the cultivar was considered stimulated after irradiation for the studied morphological trait. If the ratio was below $100 \%$, the cultivar was considered inhibited after irradiation. A ratio close to $100 \%( \pm 1-2 \%)$ was considered to have no effect of irradiation.

Next, all cultivars were ranked based on the level of manifestation of the stimulating effect. Each cultivar received a score from " 1 " to "9" (according to the number of studied cultivars). A cultivar received a rank for each morphological trait, where " 9 " was given for the maximal ratio between mean values for irradiated and control plants and " 1 " was given to the cultivar with the minimal ratio among all cultivars. Accordingly, the cultivars were scored for shoot and root lengths and for shoot and root biomasses. All four scores for each cultivar were summed up, and the total score was used for evaluation of morphological response to irradiation: the cultivar with maximal total stimulating effect was ranked first (maximal score from theoretically possible $9 \times 4=36$ ), while the cultivar with maximal growth inhibition as a result of irradiation (minimal score) was ranked last. Considering close values of morphological traits for some cultivars, for further analysis, we attributed three general groups for the studied cultivars: $\gamma$-stimulated, "no effect", and $\gamma$-inhibited cultivar.

\subsection{Irradiation and Sampling Conditions for Gene Expression Analysis}

For PCR analysis, seven out of nine cultivars were used: Grees, Eryoma, Leon, Master, Ratnik, Fedos, and Fox 1. Thus, we took $\gamma$-stimulated and $\gamma$-inhibited cultivars, and two cultivars from the "no effect" group intending to screen the most evident phenotypes. Seeds of cultivars were irradiated under the same conditions as for morphological analysis. Irradiated and control seeds were sowed within an hour after irradiation. Seeds were surface sterilized using $10 \% \mathrm{H}_{2} \mathrm{O}_{2}$ for 5 min, thoroughly rinsed in distilled water, and sowed on soaked in distilled water paper rolls. Six paper rolls per cultivar were used ( 3 paper rolls for irradiated and 3 paper rolls for control seeds); each paper roll contained around 100 seeds. Seedlings were developed under the same conditions as for morphological analysis.

After 7 days of germination, 10 largest seedlings were selected from each roll. The root tips $(4 \mathrm{~cm})$ and the shoot tops $(3 \mathrm{~cm})$ of these seedlings were simultaneously cut off and immediately placed in cryovials (roots and shoots separately) and frozen in liquid nitrogen. Thus, 84 samples (42 samples per tissue) were used for gene expression analysis.

\section{5. qPCR-RT Analysis}

Up to $100 \mathrm{mg}$ of frozen tissue were homogenized in liquid nitrogen and used for isolation of total RNA using GeneJet Plant RNA Purification kit (Thermo Fisher Scientific, Waltham, MA, USA). One microgram of total RNA was subjected to DNase I treatment (Thermo Fisher Scientific, Waltham, the USA) and subsequent cDNA synthesis using MMLV RT kit (Evrogen, Moscow, Russia), according to the manufacturer's instructions. The cDNA was diluted 1:10 with nuclease-free $\mathrm{H}_{2} \mathrm{O}$ and used as a template for the qRT-PCR reaction.

The following genes (Table 1) were chosen for analysis, based on patterns of gene expression in embryos of irradiated barley of Nur cultivar [5]: 
Table 1. The list of genes chosen for expression analysis in roots and shoots of barley cultivars with different sensitivity to seed $\gamma$-irradiation.

\begin{tabular}{|c|c|c|c|c|}
\hline № & Ensembl ID & $\begin{array}{l}\text { Name of } \\
\text { Homologues }\end{array}$ & Full Name & Biological Process \\
\hline 1 & HORVU6Hr1G053540 & SOG1 & Suppressor of gamma response 1 & DNA repair \\
\hline 2 & HORVU4Hr1G090300 & ATP1 & $\begin{array}{c}\text { Probable pterin-4-alpha-carbinolamine } \\
\text { dehydratase, chloroplastic }\end{array}$ & ABA signaling \\
\hline 3 & HORVU0Hr1G016920 & HSP7R & Heat shock $70 \mathrm{kDa}$ protein 17 & Chaperon activity \\
\hline 4 & HORVU2Hr1G018440 & PER2 & Peroxidase 2 & Antioxidant process \\
\hline 5 & HORVU6Hr1G071920 & GT7 & Probable glycosyltransferase 7 & $\begin{array}{l}\text { Biosynthesis of cell } \\
\text { wall }\end{array}$ \\
\hline 6 & HORVU1Hr1G066540 & PER1 & Peroxidase 1 & Antioxidant process \\
\hline 7 & HORVU7Hr1G046320 & CB121 & $\begin{array}{l}\text { Chlorophyll a-b binding protein 1B-21, } \\
\text { chloroplastic }\end{array}$ & Photosynthesis \\
\hline 8 & HORVU4Hr1G013840 & DIOX6 & $\begin{array}{c}\text { Probable 2-oxoglutarate-dependent } \\
\text { dioxygenase }\end{array}$ & $\begin{array}{l}\text { Anthocyanin } \\
\text { biosynthesis }\end{array}$ \\
\hline 9 & HORVU2Hr1G098860 & CIP1 & COP1-interactive protein 1 & ABA signaling \\
\hline 10 & HORVU3Hr1G109230 & CML31 & Probable calcium-binding protein CML31 & Calcium signaling \\
\hline 11 & HORVU3Hr1G095700 & MCA1 & Metacaspase-1 & Protein catabolism \\
\hline 12 & HORVU7Hr1G056820 & HFB2B & Heat stress transcription factor $\mathrm{B}-2 \mathrm{~b}$ & Chaperon activity \\
\hline 13 & HORVU5Hr1G125450 & PM19L & Membrane protein PM19L & ABA signaling \\
\hline 14 & HORVU7Hr1G117000 & ENPL & Endoplasmin homolog & Molecular chaperone \\
\hline 15 & HORVU5Hr1G113900 & $P S A E$ & $\begin{array}{c}\text { Photosystem I reaction center subunit IV, } \\
\text { chloroplastic }\end{array}$ & Photosynthesis \\
\hline 16 & HORVU2Hr1G114680 & EARLI1 & Lipid transfer protein EARLI 1 & Lipid transport \\
\hline 17 & HORVU4Hr1G066230 & AOS2 & Allene oxide synthase 2 & $\begin{array}{l}\text { Jasmonic acid } \\
\text { biosynthesis }\end{array}$ \\
\hline
\end{tabular}

Note: Names of homologous genes are taken from the closest annotated protein homologues revealed after Protein BLAST in Uniprot database. Uniprot IDs are provided in Supplementary Table S3.

The primers were designed using Primer BLAST software [11] and are listed in Supplementary Table S3. The $20 \mu \mathrm{L}$ qRT-PCR reaction consisted of $4 \mu \mathrm{L}$ of cDNA, $2 \mu \mathrm{L}$ of the primer pair mixture $(1 \mu \mathrm{M}), 4 \mu \mathrm{L}$ of qPCRmix-HS SYBR (Evrogen, Moscow, Russia), and $10 \mu \mathrm{L}$ of nuclease-free $\mathrm{H}_{2} \mathrm{O}$. The following amplification conditions were used for a DT-96 thermocycler (DNA-Technology, Moscow, Russia): initial denaturation step for $2 \mathrm{~min}$ at $95^{\circ} \mathrm{C}$, then 40 cycles of $15 \mathrm{~s}$ at $95^{\circ} \mathrm{C}$ and $60 \mathrm{~s}$ at $60^{\circ} \mathrm{C}$. The actin gene was used as housekeeping reference. All analyses were done in three biological and two technical replicates.

\subsection{Data Analysis}

Prior calculations, the morphological data were assessed for normality using Shapiro-Wilk test in Statistica 8.0 software (StatSoft, Tulsa, OK, USA). Statistica 8.0 was also used for calculations of Spearman's rank correlation coefficient and its significance. Other calculations were performed using Microsoft Office Excel 2019 software (Microsoft, Redmond, WA, USA). Length and biomass are shown as "mean $\pm \mathrm{SE}$ ". The significance of effects was estimated using the $t$-test.

Calculations of the fold change of gene expression (FC) were made using the $\Delta \Delta \mathrm{Cp}$ method in Microsoft Office Excel 2019 software. Fold changes exceeding |2| were considered significant. Correlation analysis between gene expression and morphological traits was done using Spearman's rank correlation coefficient in Statistica 8.0 software. 


\section{Results}

\subsection{Ranking of Cultivars According to Radiosensitivity}

The comparison of irradiated and control barley seedlings showed a range of responses to irradiation: growth stimulation, inhibition, and the absence of effect (Figure 1, Supplementary Figure S2). Statistically significant stimulation was found for cultivars Fox-1, Eryoma, and Master by shoot length trait and for cultivars Ratnik, Grees, and Timofey by root length. Statistically significant inhibition was found for cultivars Grees and Timofey by shoot length trait and for Eryoma, Fedos, and Leon by root length.

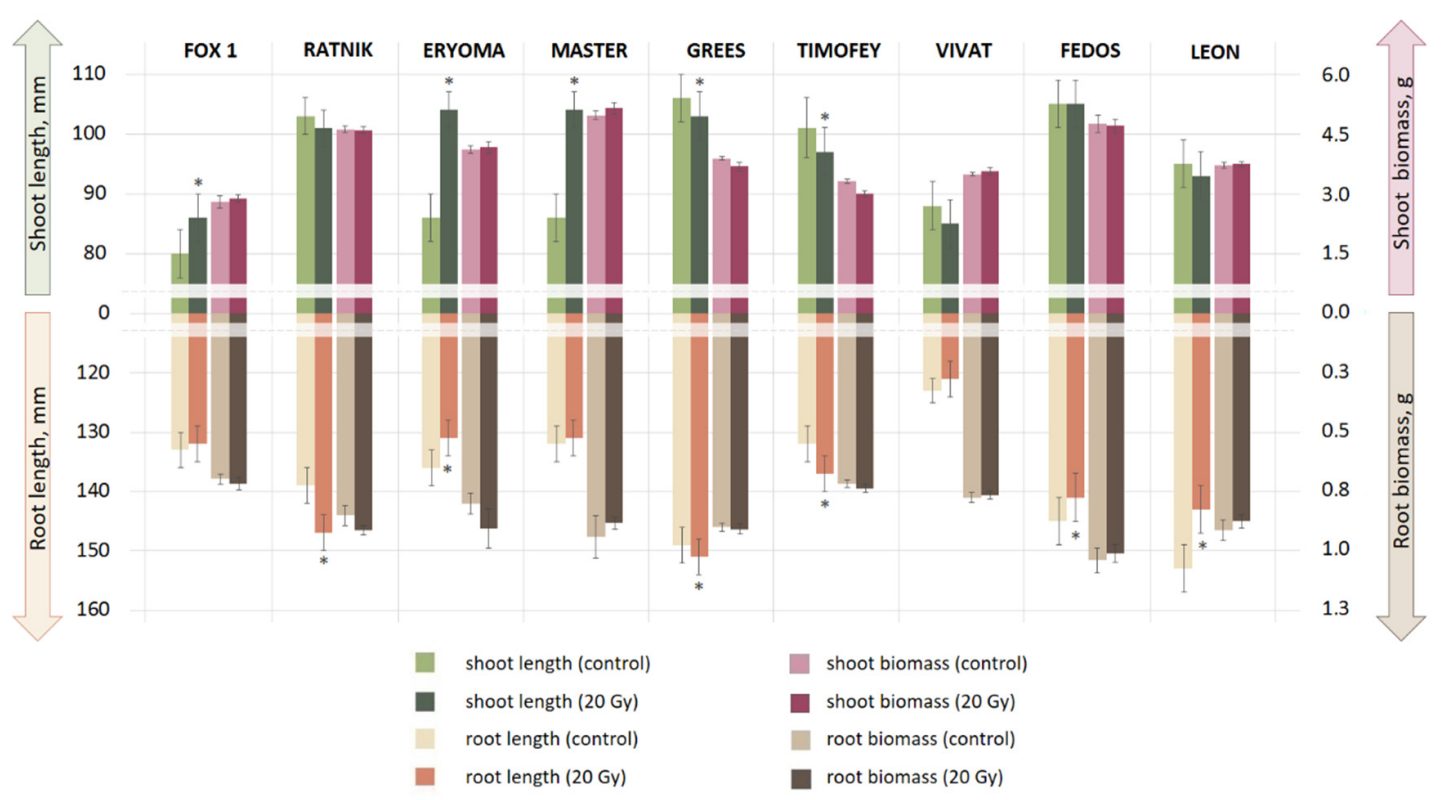

Figure 1. The effect of $20 \mathrm{~Gy} \gamma$-irradiation of seeds on morphology of seedlings. * The effect is statistically significant comparing to non-irradiated plants, $p<0.05$ (t-test).

The Figure 2 shows the results of ranking the studied cultivars based on morphological traits. For example, the cultivar Master had a maximal score " 9 " by both shoot length and biomass, while Eryoma and Ratnik cultivars received maximal scores for root biomass and length, respectively (Figure 2).

Possible maximal scores according to the sum of ranks of 4 morphological traits were equal to "36", while possible minimal scores were "4". The cultivar Fox 1 obtained a maximal score among nine cultivars (Figure 2). The cultivars Ratnik, Eryoma, and Master had at least one maximal rank among traits and took the 2nd-4th positions during ranking. The cultivar Leon had the lowest score and was ranked last among the cultivars, pointing to significant growth inhibition after $\gamma$-irradiation of seeds. The rest of the studied cultivars, Grees, Timofey, Vivat, and Fedos, obtained the 5-8th positions according to the sum of scores and were considered to have "no morphological effect" (Figure 2). Thus, the highest score received in the experiment was "27", while the lowest was "12" (Figure 2). This fact shows that we did not have a cultivar having the best (" 36 ") or worst (" 4 ") growth performance for all the traits studied but rather revealed high plasticity of original cultivars to $\gamma$-irradiation of seeds. 


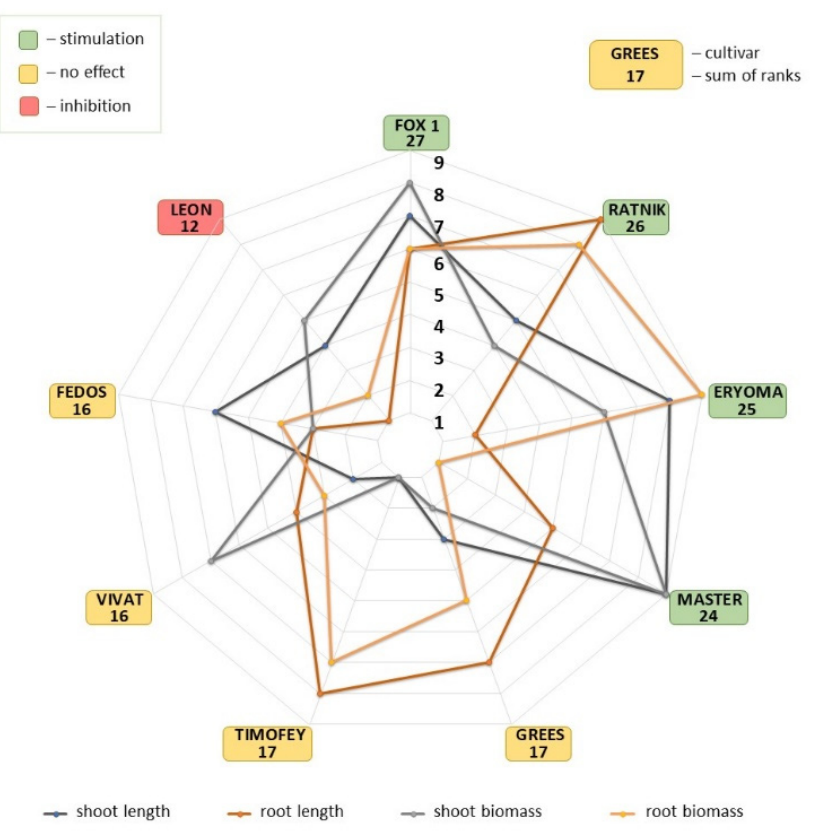

Figure 2. Ranking results reflecting radiosensitivity of the $H$. vulgare cultivars after $\gamma$-irradiation of seeds. Note: ranks from " 1 " to " 9 " were assigned to the cultivars according to changes in seedlings morphological traits after $\gamma$-irradiation of seeds ("9"-maximal stimulation, "1"-maximal inhibition).

In order to test the reliability of the approach, cultivars were also ranked by absolute values of inhibition and stimulation percent, summing up "positive" percent for stimulations of a trait and "negative" percent for inhibition. Both approaches provided comparable ranking results, dividing studied cultivars into three morphologically distant groups (Supplementary Table S4).

Several significant correlations were revealed between morphological traits: length and biomass of irradiated shoots $\left(\mathrm{r}_{\mathrm{S}}=0.79, p=0.014\right)$, length of irradiated and non-irradiated roots $\left(\mathrm{r}_{\mathrm{S}}=0.81\right.$, $p=0.008)$, biomass of non-irradiated roots and shoots $\left(\mathrm{r}_{\mathrm{S}}=0.83, p=0.005\right)$, biomass of irradiated and non-irradiated shoots $\left(\mathrm{r}_{\mathrm{S}}=0.98, p=2^{-5}\right)$, biomass of irradiated shoots and roots $\left(\mathrm{r}_{\mathrm{S}}=0.77, p=0.016\right)$, and biomass of irradiated and non-irradiated roots $\left(\mathrm{r}_{\mathrm{S}}=0.73, p=0.025\right)$ (Supplementary Table S5).

\subsection{Gene Expression Analysis in Roots and Shoots of Irradiated Plants}

The gene expression analysis was performed for the cultivars showing inhibition (Leon) and stimulation (Fox 1, Ratnik, Eryoma, and Master) and two cultivars among the "no effect" group (Grees and Fedos). The results of gene expression analysis are provided in Table 2. The expression of the PER1, CIP1, and ENPL barley homologues did not change significantly in tissues of irradiated plants for any of the seven cultivars. Differentially expressed genes were conditionally divided into several groups presented below. 
Table 2. Changes in gene expression (FC) in shoots and roots of barley seedlings grown from $\gamma$-irradiated seeds.

\begin{tabular}{|c|c|c|c|c|c|c|c|c|c|c|c|c|c|c|c|}
\hline \multirow{4}{*}{ Ensembl Name } & \multirow{4}{*}{$\begin{array}{c}\text { Short Gene } \\
\text { Name }\end{array}$} & \multicolumn{14}{|c|}{ Cultivar } \\
\hline & & \multicolumn{8}{|c|}{ Stimulation } & \multicolumn{4}{|c|}{ No Effect } & \multirow{2}{*}{\multicolumn{2}{|c|}{$\begin{array}{c}\text { Inhibition } \\
\text { Leon }\end{array}$}} \\
\hline & & \multicolumn{2}{|c|}{ Fox 1} & \multicolumn{2}{|c|}{ Ratnik } & \multicolumn{2}{|c|}{ Eryoma } & \multicolumn{2}{|c|}{ Master } & \multicolumn{2}{|c|}{ Grees } & \multicolumn{2}{|c|}{ Fedos } & & \\
\hline & & $\mathbf{R}$ & $S$ & $\mathbf{R}$ & $S$ & $\mathbf{R}$ & $S$ & $\mathbf{R}$ & $S$ & $\mathbf{R}$ & $S$ & $\mathbf{R}$ & $S$ & $\mathbf{R}$ & $S$ \\
\hline HORVU6Hr1G053540 & SOG1 & -1.9 & $\mathrm{Rad}$ & ND & ND & Ref & ND & ND & Ref & ND & ND & -2.2 & ND & 2.1 & ND \\
\hline HORVU4Hr1G090300 & ATP1 & 1.1 & ND & Ref & ND & 3.4 & -1.1 & -1.6 & 1.3 & Ref & Ref & -1.9 & Rad & 1.4 & 1.4 \\
\hline HORVU0Hr1G016920 & HSP7R & 2.3 & 1.5 & 1.6 & 1.2 & 1.4 & -1.7 & -1.6 & -1.7 & -1.1 & 1.1 & 1.5 & -1.1 & 1.0 & -1.2 \\
\hline HORVU2Hr1G018440 & PER2 & ND & ND & $\mathrm{Rad}$ & ND & ND & 2.2 & ND & ND & ND & ND & ND & 1.7 & Ref & $\mathrm{Rad}$ \\
\hline HORVU6Hr1G071920 & GT7 & Ref & ND & ND & ND & ND & ND & ND & ND & ND & ND & ND & Rad & Ref & $\mathrm{Rad}$ \\
\hline HORVU1Hr1G066540 & PER1 & ND & Ref & 1.3 & ND & ND & ND & ND & ND & -1.4 & ND & 1.7 & ND & 1.0 & ND \\
\hline HORVU7Hr1G046320 & CB121 & ND & -1.1 & ND & 1.2 & ND & -2.2 & ND & 1.2 & ND & -1.1 & ND & -1.2 & ND & -1.4 \\
\hline HORVU4Hr1G013840 & DIOX6 & 1.3 & 1.9 & 1.1 & -1.1 & 1.2 & 1.7 & 1.0 & -1.6 & -1.2 & 1.2 & 2.2 & -1.6 & 1.0 & $\mathrm{Rad}$ \\
\hline HORVU2Hr1G098860 & CIP1 & 1.6 & 1.1 & 1.0 & 1.1 & 1.2 & -1.3 & 1.0 & -1.2 & 1.2 & 1.0 & 1.2 & -1.2 & -1.1 & 1.1 \\
\hline HORVU3Hr1G109230 & CML31 & ND & ND & 8.7 & ND & 6.5 & Rad & Rad & ND & $\mathrm{ND}$ & ND & -1.1 & -1.4 & -2.9 & -1.1 \\
\hline HORVU3Hr1G095700 & MCA1 & 1.9 & 1.1 & 1.1 & 1.2 & 1.5 & -1.8 & -1.7 & -1.1 & 1.7 & 1.1 & 2.7 & -1.5 & 1.9 & 1.5 \\
\hline HORVU7Hr1G056820 & HFB2B & Ref & Rad & ND & ND & ND & ND & Ref & Rad & ND & ND & Ref & ND & ND & $\mathrm{ND}$ \\
\hline HORVU5Hr1G125450 & PM19L & 1.1 & 14.9 & 3.8 & -1.6 & 1.9 & 5.2 & -1.9 & -9.5 & 2.8 & 2.5 & 2.1 & -1.2 & -1.6 & 2.2 \\
\hline HORVU7Hr1G117000 & ENPL & 1.8 & 1.4 & 1.3 & 1.6 & 1.5 & -1.8 & -1.4 & -1.6 & -1.1 & -1.1 & 1.5 & -1.4 & 1.0 & 1.0 \\
\hline HORVU5Hr1G113900 & $P S A E$ & 1.2 & 1.1 & ND & 1.2 & 3.0 & -2.3 & 1.4 & 1.3 & ND & 1.0 & $\mathrm{Rad}$ & -1.2 & ND & -1.3 \\
\hline HORVU2Hr1G114680 & EARLI1 & ND & Ref & $\mathrm{ND}$ & ND & ND & Rad & Ref & 1.2 & $\mathrm{ND}$ & Rad & ND & 1.2 & ND & $\mathrm{Rad}$ \\
\hline HORVU4Hr1G066230 & AOS2 & 3.2 & 1.1 & 3.3 & 1.1 & 1.5 & -2.2 & 1.7 & -1.3 & 1.2 & 1.0 & $\operatorname{Ref}$ & -1.1 & -1.5 & 1.0 \\
\hline
\end{tabular}

Note: Ref—expression was revealed in non-irradiated samples only; Rad—expression was revealed in irradiated samples only; ND—no expression detected; R—roots; and S—shoots. Fold changes $\geq|2|$ are in bold. 


\subsubsection{General Comparison of Gene Expression among Different Organs of Irradiated Cultivars}

The expression of some studied genes was tissue-specific (Table 2). SOG1, ATP1, and CML31 barley homologues were mainly expressed in roots, while shoot expression was occasional. HSP7R, DIOX6, CIP1, MCA1, PM19L, ENPL, PSAE, and AOS2 homologue expressions were detected in both tissues. EARLI and PER2 homologue transcriptional activities were consistently recorded only in shoots of several cultivars. Oppositely, PER1 expression was detected only in roots. GT7 homologue expression was found in roots of non-irradiated plants of several cultivars. Chlorophyll-binding protein $C B 121$ expression, as expected, was triggered only in leaves. HFB2B expression was detected in roots of non-irradiated and leaves of irradiated plants.

\subsubsection{Differentially Expressed Genes in "No Effect" and $\gamma$-Inhibited Cultivars}

The homologue of the transcription factor induced by DNA damage, SOG1, was downregulated in roots of "no effect" cultivar Fedos, while $\gamma$-inhibited Leon had a higher expression of this gene in comparison with non-irradiated control plants (Table 2). Genes encoding a homologue of 2-oxoglutaratedependent dioxygenase DIOX6, participating in jasmonate biosynthesis, were upregulated in roots of the Fedos cultivar. The homologue of metacaspase MCA1 was also upregulated in roots of Fedos (Table 2). Thus, the expression levels of homologues of SOG1, DIOX6, and MCA1 were significantly changed in roots of the cultivar that did not exhibit morphological changes after irradiation, and the expression level of DNA damage-related SOG1 was higher in roots of $\gamma$-inhibited cultivar.

\subsubsection{Differentially Expressed Genes in $\gamma$-Stimulated Cultivars}

The expression of the HSP7R homologue, encoding a heat shock protein, was significantly induced (Table 2) only in the cultivar with the highest stimulation rank (Fox 1). The ATP1 homologue, the product of which is involved in abscisic acid (ABA) signaling, was upregulated in the roots of the $\gamma$-stimulated cultivar Eryoma (Table 2). The Eryoma cultivar was also characterized by upregulation of the peroxidase PER2 homologue in shoots and by downregulation of the CB121 homologue, which encodes the chlorophyll-binding protein (Table 2). The photosystem I reaction center subunit homologue PSAE was differentially expressed in both shoots and roots of the Eryoma cultivar, being upregulated in roots and downregulated in shoots (Table 2). The product of the AOS2 homologue is involved in jasmonic acid biosynthesis, and its expression was upregulated in roots of two most $\gamma$-stimulated cultivars Fox 1 and Ratnik and downregulated in shoots of the Eryoma cultivar (Table 2). Therefore, the expression levels of homologues of the HSP7R, ATP1, PER2, CB121, AOS2, and PSAE genes were significantly changed in $\gamma$-stimulated cultivars.

The homologue of heat stress-induced transcription factor B-2b HFB2b, which controls chaperon activity, showed a reversed pattern of expression for roots and shoots of irradiated and non-irradiated plants (Table 2). In $\gamma$-stimulated cultivars Fox 1 and Master, the expression of $H F B 2 b$ was revealed in roots of non-irradiated plants, being abruptly stopped after irradiation, and the opposite situation occurred for shoots: no expression was revealed for shoots of control plants, while after irradiation, the expression of this gene was recorded.

\subsubsection{Genes Expressed only for Irradiated or Non-Irradiated Plants}

The expression of the homologue of probable glycosyltransferase GT7 that participates in biosynthesis of cell wall components was recorded in shoots of irradiated plants of the Leon and Fedos cultivars (Table 2). In non-irradiated samples, the expression of this gene was found only in roots of the most stimulated cultivar Fox 1 and the most inhibited cultivar Leon, suggesting irrelevance of the root expression of this gene for the morphological effect of $\gamma$-irradiation of seeds.

Genes encoding the homologue of EARLI1 lipid transfer protein also showed an interesting pattern of expression in shoots of irradiated plants (Table 2). For the most $\gamma$-stimulated cultivar Fox 1, we revealed the expression of this gene only in shoots of control plants and not after irradiation, while 
the shoot tissues of the less stimulated cultivar Eryoma, "no effect" cultivar Grees, and $\gamma$-inhibited cultivar Leon were characterized by expression of this gene only after irradiation. This make EARLI1 a plausible target molecule for studying the reasons of growth inhibition after $\gamma$-irradiations of seeds.

\subsubsection{Expression of Putative Target Genes PM19L and CML31}

The expressions of homologues of PM19L and CML31 appear to play an important role in barley response to seed $\gamma$-irradiation (Table 2). PM19L encodes a membrane protein PM19L, which is involved in ABA signaling. This gene was significantly upregulated in $\gamma$-stimulated cultivars Fox $\mathbf{1}$ and Eryoma (shoots) and Ratnik (roots); however, in the less-stimulated Master, this gene had significantly lower expression than in non-irradiated plants. In "no effect" cultivars Grees (roots and shoots) and Fedos (roots) and $\gamma$-inhibited cultivar Leon (shoots), expression of the PM19L homologue was also increased; however, the fold changes of expression levels were generally lower than for $\gamma$-stimulated cultivars (Table 2).

CML31 encodes in rice (Oryza sativa subsp. japonica) probable calcium-binding protein CML31. The expression of its homologue in barley plants after seed $\gamma$-irradiation appears only in irradiated plants for cultivars Eryoma (shoots) and Master (roots) or is characterized by upregulation in roots (cultivars Ratnik and Eryoma); this gene is also downregulated in $\gamma$-inhibited cultivar Leon.

\subsection{Correlations between Morphological Traits and Gene Expression}

Several significant correlation coefficients between morphological traits and gene expression in seedlings after $\gamma$-irradiation of seeds were revealed in our study, comparing morphological traits of all cultivars with a respective level of gene expression FC in roots and shoots (Supplementary Table S5). The expression of the ATP1 homologue in shoots negatively correlated with root biomass $\left(\mathrm{r}_{\mathrm{s}}=-0.99\right)$. PER1 homologue expression in roots showed a significant positive correlation with shoot biomass $\left(r_{s}=0.99\right)$. The expression of the DIOX6 homologue in shoots negatively correlated with shoot biomass $\left(\mathrm{r}_{\mathrm{s}}=-0.88, p=0.054\right)$. The expression of the $M C A 1$ homologue in shoots negatively correlated with shoot length $\left(\mathrm{r}_{\mathrm{s}}=-0.78, p=0.038\right)$. PM19L homologue expression in shoots showed a significant negative correlation with shoot biomass $\left(\mathrm{r}_{\mathrm{s}}=-0.86, p=0.014\right)$, and its expression in roots was positively associated with root biomass $\left(r_{\mathrm{s}}=0.75, p=0.052\right)$. Expression of the AOS2 homologue in shoots negatively correlated with shoot length $\left(\mathrm{r}_{\mathrm{s}}=-0.79, p=0.035\right)$.

Targeting future research, coefficients of correlation exceeding 0.6 also can be considered (Supplementary Table S5). For example, the expression of the PM19L homologue in roots positively correlated with root length $\left(\mathrm{r}_{\mathrm{s}}=0.67, p=0.102\right)$. Expression of the ATP1 homologue in shoots negatively correlated with the shoot length $\left(\mathrm{r}_{\mathrm{s}}=-0.87, p=0.333\right)$ and positively correlated with the root length $\left(\mathrm{r}_{\mathrm{s}}=-0.87, p=0.333\right)$.

\section{Discussion}

In this work, we provided an analysis of morphological traits of barley seedlings belonging to different cultivars, which grew from seeds irradiated by low dose of $\gamma$-radiation (20 Gy). Original high-quality seeds were found to have different types of response to the same dose of irradiation, suggesting the important role of genotype in radiation stimulation occurrence (Figure 2). In order to reveal possible molecular targets as determinants of radiation hormesis effect, we studied the expression of a broad range of genes, products of which perform different biological functions (Table 1): DNA repair; $\mathrm{ABA}$ and calcium signaling; photosynthesis; biosynthesis of cell wall components, antocyanins, and jasmonic acid; protein catabolism; lipid transport; and genes encoding proteins with chaperone or antioxidant activities. All these candidate genes were revealed during our previously performed transcriptome studies of irradiated embryos of barley cultivar Nur [5] as interesting targets to study radiation hormesis effect. The aim of this work was to reveal which of these target genes have universal role in hormesis effect for different cultivars. 


\subsection{Morphological Responses of Seedlings to Seed $\gamma$-Irradiation}

Coordination among plant morphological traits is often expressed by positive and negative correlations, representing trade-offs and allometries based on physiological requirements in response to environmental conditions [12]. In our study, several significant correlations were revealed between morphological traits of control and irradiated plants. Correlations between two traits of control plants or a trait of control and a trait of irradiated plant seem to be cultivar-specific responses. However, the existence of correlations, occurring only for irradiated plants but not for control (such as length and biomass of irradiated shoots, and biomass of irradiated shoots and roots) reflects the possibility of metabolic reallocations, which was also shown for the metabolome of irradiated barley of the Nur cultivar [6]. Indeed, there is evidence that plants adjust the allocation of carbon and nutrients between their organs under different environmental conditions and stress factors exposure [12]. Such reallocations during metabolic adjustments under stress could be a reason for enhanced phenotypic plasticity of a given phenotype, which is also known as an adaptive phenotypic plasticity [13].

The tendency to retain constant growth parameters occurs in the case of environmental perturbations of moderate intensity and short duration relative to the growth rate and can be related to the interplay of metabolic pools [14]. Most of $\gamma$-stimulated cultivars had the same values of morphological traits as non-irradiated plants. These cultivars were able to maintain homeostasis under harsh conditions of seed $\gamma$-irradiation, which also reflects their low sensitivity to inhibitory effects of radiation exposure (Supplementary Table S4, Figure 1).

\subsection{Gene Expression in $\gamma$-Inhibited and "No Effect" Cultivars}

The study of a range of different cultivars allows to separate genes nonspecifically responding to seed $\gamma$-irradiation from those that can be directly involved in radiation hormesis establishment. In our experiment, such nonspecific genes were those significantly differentially regulated only in the cultivars from "no effect" and inhibited groups (Grees, Fedos, and Leon).

SOG1 participates in transcriptional response to DNA damage, cell cycle arrest, and programmed cell death. As a transcription factor, SOG1 in Arabidopsis thaliana plays a crucial role in transcriptional regulation of more than 100 genes associated with these responses [15]. Significant induction of the SOG1 homologue in roots of the most inhibited cultivar Leon (Table 2) suggests the accumulation of a high number of DNA double-strand breaks [16] even 7 days after irradiation of seeds, showing that this sensitivity to the low-dose irradiation cultivar may have less effective DNA repair machinery. However, SOG1 appears not to be involved directly in eustress responses because its expression was suppressed in roots of "no effect" cultivar Fedos and $\gamma$-stimulated cultivar Fox 1. Alternatively, for those cultivars, SOG1 expression might be induced at the earliest stage of development, and DNA repair processes might have been completed to the time when measurements were taken.

The MCA1 homologue had higher expression in the roots of cultivar Fedos (Table 2), which showed no morphological changes after irradiation (Figure 2). Its homologue in Arabidopsis thaliana, AT1G02170, encodes a type I metacaspase, which belongs to a class of cysteine-dependent proteases, playing an essential role in programmed cell death [17]. MCA1 is thought to have a pro-survival homeostatic function in aging plants, working in parallel with the autophagy process [18]. In barley, the homologue of MCA1 is thought to be one of the modulators of programmed cell death for alleviating stress damage [19]. The expression of MCA1 homologue in our experiment had a significant negative correlation with shoot length (Supplementary Table S5). Therefore, activation of programmed cell death can be one of the reasons for a reduction of linear size and biomass of seedlings in a relatively more radiosensitive cultivar Fedos.

Several evidence confirming jasmonic acid (JA) signaling involvement in responses to ionizing radiation were found in this work. In plants, the hormone jasmonic acid and its derivatives regulate plant response to biotic and abiotic stressors [20,21]. Jasmonates are also associated with the formation of a radiation-induced bystander effect in plants [22]. Immediately after accumulation of JA, the hormone 
is metabolized, presumably to prevent the inhibitory effect of high levels of JA on growth and development, and 12-OH-JA is one of the forms of inactive JA [20]. In the current study, the DIOX6 homologue is upregulated in roots of cultivar Fedos (Table 2), while its product inhibits jasmonate signaling through 12-OH-jasmonate synthesis [23]. In the $\gamma$-inhibited cultivar Leon, the expression of this gene in shoots was revealed after irradiation only. Therefore, in more radiosensitive cultivars ("no effect" and $\gamma$-inhibited), jasmonate accumulation may be disrupted.

\subsection{Gene Expression in $\gamma$-Stimulated Cultivars}

A significant deregulation of gene expression only in $\gamma$-stimulated cultivars can point to possible target genes inducing a radiation stimulation effect. While the DIOX6 homologue inactivates jasmonate, AOS2 is a homologue of AT5G42650, which encodes a member of the cytochrome P450 gene family that functions as an allene oxide synthase. This enzyme catalyzes dehydration of the hydroperoxide to an unstable allene oxide in the JA biosynthetic pathway [21]. In roots of $\gamma$-stimulated cultivars Fox 1 and Ratnik, the expression of AOS2 homologue is enhanced. The significant induction of the JA biosynthesis pathway in shoots was not found (Table 2), probably because it could lead to accumulation of JA and subsequent growth inhibition, while expression of the AOS2 homolog in shoots negatively correlated with shoot length $\left(r_{s}=-0.79, p=0.035\right)$ (Supplementary Table S5). Therefore, jasmonate signaling in roots of irradiated plants can be a possible target for the further studies of radiation hormesis effect determinants.

Reactive oxygen species (ROS) are produced by plants during normal cell metabolism, and their production is significantly increased under stress conditions [24]. ROS signals work upstream and downstream from many other second messengers, and these molecules can directly or indirectly regulate expression of many genes, including those related to growth and development [25]. Radiation exposure provokes overproduction of ROS [8], and this can change the redox state of chloroplasts [26] and eventually influence photosynthetic processes [5]. The PSAE homologue encodes photosystem I (PSI) reaction center subunit IV, which stabilizes the interaction between PSI subunits and takes part in ferredoxin metabolism [24]. The expression of this gene was downregulated in shoots of the Eryoma cultivar and was upregulated in roots (Table 2). A. thaliana mutants deficient in PsaE1 had stunted growth, was pale, suffered from enhanced PSII photoinhibition, and showed a lower level of P700 oxidation under steady-state conditions [24]. In the Eryoma cultivar, we also found a decrease in shoot expression of the CB121 homologue encoding chlorophyll a-b binding protein 1B-21. The CB121 protein captures and delivers the excitation energy to the photosystems. Moreover, the expression of the PER2 homologue, which encodes peroxidase 2, was upregulated in shoots of the same cultivar (Table 2). Increased expression of the peroxidase gene and suppression of the genes of the photosynthetic apparatus suggest oxidative stress development in leaves of the Eryoma cultivar. Meanwhile, root biomass of this cultivar was maximal among all cultivars studied. Such changes in gene expression may be interpreted as an attempt to regulate redox metabolism by reduction of the photosynthetic intensity and activation of the antioxidant system. Suppression of the PSAE and CB121 genes in shoots can be attributed to growth conditions: seedlings were grown in the dark, and the process of photosynthesis did not play a significant role in their development. The source-sink relationship that allows the Eryoma cultivar to accumulate root biomass under photosynthetic suppression can be a research question for future studies.

ATP1 is a positive regulator of the expression of the transcriptional bZIP factor ABI5, one of the main transcription factors interacting with ABA and controlling germination and developmental delay after germination [27]. In roots of the Eryoma cultivar, the ATP1 homologue was upregulated (Table 2). Among stimulated cultivars, Eryoma showed a response that was previously recorded in the transcriptome of $\gamma$-inhibited (100 Gy) embryos of lower-quality seeds of the Nur cultivar [5], characterized by increased peroxidases activity, suppressed photosynthetic processes, and ABA-signaling induction. The absence of growth inhibition in the Eryoma cultivar can be attributed to high plasticity of high-quality original seeds, stressing out the importance of grain quality for stress tolerance of crops. 


\subsection{Genes Expressed Only for Irradiated or Non-Irradiated Plants}

The induction of GT7 homologue expression in the shoots of irradiated cultivars Fedos and Leon may reflect the damage of cell wall components by $\gamma$-irradiation. The homologue of this gene in A. thaliana, AT2G22900, encodes a galactomannan-1,6-galactosyltransferase MUCI10, which controls the degree of galactosylation of cell wall components and is important for the structure of cellulose, mucilage density, and adherence of pectin [28]. Another cell wall-associated protein is EARLI1, and the expression of its gene is induced in shoots of several cultivars after irradiation, while in the cultivar Fox 1 with the highest score, its expression was observed only in shoots of non-irradiated control plants. The upregulation of the EARLI1 gene is associated with ABA response and stress tolerance during early seedling development [29], which also confirms the higher level of stress responses in seedlings of more radiosensitive cultivars.

\subsection{PM19L and CML31-Putative Target Genes}

PM19L and CML31 homologue expressions were almost ubiquitous in $\gamma$-irradiated cultivars, with significant fold changes of expression and correlation with morphological traits. Based on these reasons, PM19L-like and CML31-like genes were considered the most promising genes for involvement in radiation hormesis across different cultivars. The PM19L homologue in A. thaliana, AT1G04560, belongs to the AWPM-19-like protein family, which is involved in abiotic stress response through ABA-dependent signaling [30]. To date, many authors have recorded that PM19 responds to abiotic stress and is capable of changing seed dormancy. In rice, the expression of PM19L was induced by heat shock, drought, cold, salt stresses, and ABA treatment [31,32]. In A. thaliana, the knockout of this gene produced seeds with increased primary and secondary dormancy [30]. A. thaliana pm19l1 mutants show reduced germination under salt or osmotic stresses [33].

Under stress conditions, the expression of rice homologue OsPM19L1 was enhanced in a rice mutant deficient in ABI5, suggesting that ABI5 negatively regulates PM19L gene expression and that PM19L is closely associated with stress tolerance through the ABA-dependent pathway in rice [32]. ATP1 is a positive regulator of ABI5 expression [27], and ABI5 negatively regulates the expression of the PM19L gene [32]. Importantly, when the PM19L homologue was upregulated in our experiment, the expression of ATP1 usually was not identified or downregulated (Table 2). In our previous study, the expression of PM19L gene in embryos of the $\gamma$-stimulated cultivar Nur was downregulated in $24 \mathrm{~h}$ under 20 Gy irradiation, and the ABA concentration in seedlings was reduced [5,34]. Upregulation of the PM19L homologue may be induced by an increase in ABA levels [32], and such an upregulation was observed in shoots of the $\gamma$-stimulated cultivars Fox 1 and Eryoma and to a lesser extent in the $\gamma$-inhibited cultivar Leon (Table 2). A significant negative correlation of the PM19L homologue expression and shoot biomass $\left(\mathrm{r}_{\mathrm{s}}=-0.86, p=0.014\right)$ (Supplementary Table S5), together with inhibition of photosynthetic processes in the Eryoma cultivar indeed can point to the moderate ABA suppression of growth processes in shoots. An opposite situation was revealed for PM19L expression in roots, which positively correlated with the root biomass $\left(\mathrm{r}_{\mathrm{s}}=0.75, p=0.052\right)$ (Supplementary Table S5).

The PM19L protein is probably associated with membranes and can be involved in ion transport [30]. Genes of this family can be directly involved in ABA transport and confer drought tolerance by overexpression [35]. Barrero et al. [30] suggested that PM19 proteins could play a role in modifying the membrane properties and could thus modulate responses to temperature. It was shown that the barley PM19 gene was induced in the grain by heat stress [36], and in wheat, the expression of homologous TaPM19-A1 was suppressed by high temperatures during grain maturation, thus leading to a decay in dormancy [37].

Thus, the expression of PM19L appears to depend on cultivar and probably is connected with ABA signaling modulations. The increased tolerance of $P M 19 L$ overexpressors to various stress factors and its significant deregulation, especially in $\gamma$-stimulated cultivars (Table 2), makes this gene a promising target for upcoming studies on radiation hormesis mechanisms. 
Much less information is available for the next possible target gene, the CML31 homologue. Calcium $\left(\mathrm{Ca}^{2+}\right)$ is a known regulator of growth and development of plants, an important factor for cell wall and membrane stability [38], and a significant secondary messenger that regulates the activities of hormonal and environmental signals that are associated with biotic and abiotic stresses [39]. Calmodulin-like CML31 homologue expression is induced in root tissues tolerant to seed $\gamma$-irradiation plants and decreased in the sensitive cultivar Leon (Table 2). This gene is a homologue of CML39 (AT1G76640) encoding a calcium sensor that is important for various developmental processes from seeds to mature plants. CML39 functions in A. thaliana as a $\mathrm{Ca}^{2+}$ sensor that plays an important role in the transduction of light signals that promote seedling establishment [40]. Germination of $\mathrm{cml} 39$ seeds was less sensitive than the wild-type to inhibition by ABA or by treatments that impaired gibberellic acid biosynthesis [41]. CML39 plays a role in stress responses [39,40], and CML proteins per se take part in transduction of $\mathrm{Ca}^{2+}$ sensors during abiotic stress adaptation [42]. The increase of CML31 homologue expression in roots of $\gamma$-stimulated cultivars can point to an important role of calcium and ABA signaling during radiation hormesis effect establishment and makes this gene a suitable candidate for deeper exploration of barley growth stimulation after low-dose irradiation of seeds.

\section{Conclusions}

To search for possible determinants of radiation hormesis, we have studied the differential gene expression in shoots and roots of barley seedlings of seven cultivars with different sensitivity to low-dose $\gamma$-irradiation of seeds. Genes were chosen based on previously performed transcriptomic analysis of barley embryos [5]. Of the 17 selected candidate genes, 11 genes changed their expression in plants irradiated at a dose of $20 \mathrm{~Gy}$. These results, obtained on certified seeds of several cultivars, confirmed the possibility of using a transcriptome analysis to search for candidate genes of the radiation hormesis effect.

Morphological traits of barley seedlings grown from $\gamma$-irradiated seeds allowed for sorting the studied cultivars by radiosensitivity: $\gamma$-stimulated, "no morphological effect", and $\gamma$-inhibited. Morphological analysis and differential expression of candidate genes indicated that high-quality seeds respond differently to low doses of $\gamma$-radiation, depending on cultivar. Deregulated genes in "no effect" and $\gamma$-inhibited cultivars are likely involved in nonspecific response to seed $\gamma$-irradiation (homologues of SOG1, DIOX6, and MCA1). On the contrary, differentially regulated genes in $\gamma$-stimulated cultivars can be directly involved in radiation hormesis establishment. We identified homologues of PM19L and CML31 as promising targets for future research regarding the mechanisms of stimulatory effect after low-dose irradiation. The homologue of AOS2 related to jasmonate signaling can also be a possible target for future studies.

Overall, our study indicates the important role of genotype in radiation hormesis establishment. The obtained data on the differential gene expression expanded the knowledge on the molecular pathways involved in the stimulation effect, and the proposals of universal target genes for different barley cultivars can be the basis for future studies aimed at obtaining more stress-tolerant cultivars. However, future attempts must be directed to the deciphering of hubs connecting different signaling pathways that respond to low-dose irradiation.

Supplementary Materials: The following are available online at http://www.mdpi.com/2073-4395/10/11/1837/s1: Table S1: Information about barley cultivars; Table S2: Primary data on morphological trait measurement for seedlings of control and irradiated seeds of several barley cultivars; Table S3: Information about candidate genes and primer pair sequences; Table S4: Ranking according to the relative values (\%) of growth changes after irradiation; Table S5: Spearman's coefficients of correlation between morphological traits and gene expression; Figure S1: Example of measurements after the 7th day of germination (cultivar Fox-1); Figure S2: The effect of 20 Gy $\gamma$-irradiation of seeds on the morphology of seedlings.

Author Contributions: Conceptualization, P.Y.V.; methodology, P.Y.V., E.A.K., V.S.B.; software, I.V.G., E.A.K., M.S.P., P.Y.V.; validation, I.V.G., E.A.K.; formal analysis, E.A.K., M.S.P., I.V.G., P.Y.V.; investigation, I.V.G., E.A.K., I.A.P., P.Y.V., E.S.M., S.V.B., M.A.L., A.S.S., T.V.C., V.S.B.; resources, A.A.D., D.P.D.; writing-original draft preparation, P.Y.V. and E.A.K.; writing—review and editing, all co-authors; visualization, I.V.G., E.A.K., M.S.P.; 
supervision, P.Y.V.; funding acquisition, P.Y.V. All authors have read and agreed to the published version of the manuscript.

Funding: The work has been supported by the Ministry of Science and Higher Education of the Russian Federation, project 0627-2019-0003.

Conflicts of Interest: The authors declare no conflict of interest.

\section{References}

1. Agathokleous, E.; Kitao, M.; Calabrese, E.J. Hormesis: Highly generalizable and beyond laboratory. Trends Plant Sci. 2020. [CrossRef]

2. Vázquez-Hernández, M.C.; Parola-Contreras, I.; Montoya-Gómez, L.M.; Torres-Pacheco, I.; Schwarz, D.; Guevara-González, R.G. Eustressors: Chemical and physical stress factors used to enhance vegetables production. Sci. Hortic. 2019, 250, 223-229. [CrossRef]

3. Araújo, S.d.S.; Paparella, S.; Dondi, D.; Bentivoglio, A.; Carbonera, D.; Balestrazzi, A. Physical methods for seed invigoration: Advantages and challenges in seed technology. Front. Plant Sci. 2016, 7. [CrossRef]

4. Gudkov, S.V.; Grinberg, M.A.; Sukhov, V.; Vodeneev, V. Effect of ionizing radiation on physiological and molecular processes in plants. J. Environ. Radioact. 2019, 202, 8-24. [CrossRef] [PubMed]

5. Volkova, P.Y.; Duarte, G.T.; Soubigou-Taconnat, L.; Kazakova, E.A.; Pateyron, S.; Bondarenko, V.S.; Bitarishvili, S.V.; Makarenko, E.S.; Churyukin, R.S.; Lychenkova, M.A.; et al. Early response of barley embryos to low- and high-dose gamma irradiation of seeds triggers changes in the transcriptional profile and an increase in hydrogen peroxide content in seedlings. J. Agron. Crop Sci 2020, 206, 277-295. [CrossRef]

6. Volkova, P.Y.; Clement, G.; Makarenko, E.S.; Kazakova, E.A.; Bitarishvili, S.V.; Lychenkova, M.A. Metabolic profiling of $\gamma$-irradiated barley plants identifies reallocation of nitrogen metabolism and metabolic stress response. Dose-Response 2020, 18, 155932582091418. [CrossRef]

7. Agathokleous, E.; Calabrese, E.J. Hormesis can enhance agricultural sustainability in a changing world. Glob. Food Secur. 2019, 20, 150-155. [CrossRef]

8. De Micco, V.; Arena, C.; Pignalosa, D.; Durante, M. Effects of sparsely and densely ionizing radiation on plants. Radiat. Environ. Biophys. 2011, 50,1-19. [CrossRef]

9. Penfield, S. Seed dormancy and germination. Curr. Biol. 2017, 27, 874-878. [CrossRef]

10. Geras'kin, S.; Churyukin, R.; Volkova, P. Radiation exposure of barley seeds can modify the early stages of plants' development. J. Environ. Radioact. 2017, 177, 71-83. [CrossRef]

11. Ye, J.; Coulouris, G.; Zaretskaya, I.; Cutcutache, I.; Rozen, S.; Madden, T. Primer-BLAST: A tool to design target-specific primers for polymerase chain reaction. BMC Bioinform. 2012, 13, 134. [CrossRef] [PubMed]

12. Kleyer, M.; Trinogga, J.; Cebrián-Piqueras, M.A.; Trenkamp, A.; Fløjgaard, C.; Ejrnæs, R.; Bouma, T.J.; Minden, V.; Maier, M.; Mantilla-Contreras, J.; et al. Trait correlation network analysis identifies biomass allocation traits and stem specific length as hub traits in herbaceous perennial plants. J. Ecol. 2018. [CrossRef]

13. Nicotra, A.B.; Davidson, A. Adaptive phenotypic plasticity and plant water use. Funct. Plant Biol. 2010, 37, 117-127. [CrossRef]

14. Giordano, M. Homeostasis: An underestimated focal point of ecology and evolution. Plant Sci. 2013, 211, 92-101. [CrossRef] [PubMed]

15. Mahapatra, K.; Roy, S. An insight into the mechanism of DNA damage response in plants- role of SUPPRESSOR OF GAMMA RESPONSE 1: An overview. Mutat. Res. Fundam. Mol. Mech. Mutagen. 2020, 819-820, 111689. [CrossRef]

16. Yoshiyama, K.O.; Aoshima, N.; Takahashi, N.; Sakamoto, T.; Hiruma, K.; Saijo, Y.; Hidema, J.; Umeda, M.; Kimura, S. SUPPRESSOR OF GAMMA RESPONSE 1 acts as a regulator coordinating crosstalk between DNA damage response and immune response in Arabidopsis thaliana. Plant Mol. Biol. 2020, 103, 321-340. [CrossRef]

17. Yao, S.; Luo, S.; Pan, C.; Xiong, W.; Xiao, D.; Wang, A.; Zhan, J.; He, L. Metacaspase MC1 enhances aluminum-induced programmed cell death of root tip cells in Peanut. Plant Soil 2020, 448, 479-494. [CrossRef]

18. Coll, N.S.; Smidler, A.; Puigvert, M.; Popa, C.; Valls, M.; Dangl, J.L. The plant metacaspase AtMC1 in pathogen-triggered programmed cell death and aging: Functional linkage with autophagy. Cell Death Differ. 2014, 21, 1399-1408. [CrossRef] 
19. Shamloo-Dashtpagerdi, R.; Lindlöf, A.; Aliakbari, M.; Pirasteh-Anosheh, H. Plausible association between drought stress tolerance of barley (Hordeum vulgare L.) and programmed cell death via MC1 and TSN1 genes. Physiol. Plant. 2020, 170, 46-59. [CrossRef]

20. Caarls, L.; Elberse, J.; Awwanah, M.; Ludwig, N.R.; de Vries, M.; Zeilmaker, T.; Van Wees, S.C.M.; Schuurink, R.C.; Van den Ackerveken, G. Arabidopsis JASMONATE-INDUCED OXYGENASES down-regulate plant immunity by hydroxylation and inactivation of the hormone jasmonic acid. Proc. Natl. Acad. Sci. USA 2017, 114, 6388-6393. [CrossRef]

21. Rustgi, S.; Springer, A.; Kang, C.; von Wettstein, D.; Reinbothe, C.; Reinbothe, S.; Pollmann, S. ALLENE OXIDE SYNTHASE and HYDROPEROXIDE LYASE, two non-canonical cytochrome P450s in Arabidopsis thaliana and their different roles in plant defense. IJMS 2019, 20, 3064. [CrossRef] [PubMed]

22. Wang, T.; Xu, W.; Deng, C.; Xu, S.; Li, F.; Wu, Y.; Wu, L.; Bian, P. A pivotal role of the jasmonic acid signal pathway in mediating radiation-induced bystander effects in Arabidopsis thaliana. Mutat. Res. Fundam. Mol. Mech. Mutagen. 2016, 791-792, 1-9. [CrossRef] [PubMed]

23. Nakamura, Y.; Mithöfer, A.; Kombrink, E.; Boland, W.; Hamamoto, S.; Uozumi, N.; Tohma, K.; Ueda, M. 12-Hydroxyjasmonic acid glucoside is a COI1-JAZ-independent activator of leaf-closing movement in Samanea saman. Plant Physiol. 2011, 155, 1226-1236. [CrossRef] [PubMed]

24. Krieger-Liszkay, A.; Shimakawa, G.; Sétif, P. Role of the two PsaE isoforms on $\mathrm{O}_{2}$ reduction at photosystem I in Arabidopsis thaliana. Biochim. Biophys. Acta (Bba) Bioenerg. 2020, 1861, 148089. [CrossRef]

25. Sewelam, N.; Kazan, K.; Schenk, P.M. Global plant stress signaling: Reactive oxygen species at the cross-road. Front. Plant Sci. 2016, 7, 187. [CrossRef]

26. Suzuki, N.; Koussevitzky, S.; Mittler, R.; Miller, G. ROS and redox signalling in the response of plants to abiotic stress: ROS and redox signalling in plants. Plant Cell Environ. 2012, 35, 259-270. [CrossRef]

27. Zhang, H.; Cui, F.; Wu, Y.; Lou, L.; Liu, L.; Tian, M.; Ning, Y.; Shu, K.; Tang, S.; Xie, Q. The RING finger ubiquitin E3 ligase SDIR1 targets SDIR1-INTERACTING PROTEIN1 for degradation to modulate the salt stress response and ABA signaling in Arabidopsis. Plant Cell 2015, 27, 214-227. [CrossRef]

28. Voiniciuc, C.; Schmidt, M.H.-W.; Berger, A.; Yang, B.; Ebert, B.; Scheller, H.V.; North, H.M.; Usadel, B.; Günl, M. MUCILAGE-RELATED10 produces galactoglucomannan that maintains pectin and cellulose architecture in Arabidopsis seed mucilage. Plant Physiol. 2015, 169, 403-420. [CrossRef]

29. Xu, D.; Huang, X.; Xu, Z.-Q.; Schläppi, M. The HyPRP gene EARLI1 has an auxiliary role for germinability and early seedling development under low temperature and salt stress conditions in Arabidopsis thaliana. Planta 2011, 234, 565-577. [CrossRef]

30. Barrero, J.M.; Dorr, M.M.; Talbot, M.J.; Ishikawa, S.; Umezawa, T.; White, R.G.; Gubler, F. A role for PM19-Like 1 in seed dormancy in Arabidopsis. Seed Sci. Res. 2019, 29, 184-196. [CrossRef]

31. Rerksiri, W.; Zhang, X.; Xiong, H.; Chen, X. Expression and promoter analysis of six heat stress-inducible genes in rice. Sci. World J. 2013, 2013, 1-9. [CrossRef] [PubMed]

32. Chen, H.; Lan, H.; Huang, P.; Zhang, Y.; Yuan, X.; Huang, X.; Huang, J.; Zhang, H. Characterization of OsPM19L1 encoding an AWPM-19-like family protein that is dramatically induced by osmotic stress in rice. Genet. Mol. Res. 2015, 14, 11994-12005. [CrossRef] [PubMed]

33. Ross, A.D.; Castillejo-Pons, P.; Alsaif, O.; Stahl, Y.; Seale, M.; Morris, P.C. The conserved plant PM19 protein functions as an osmosensor and regulator of germination. bioRxiv 2020. [CrossRef]

34. Bitarishvili, S.V.; Volkova, P.Y.; Geras'kin, S.A. $\gamma$-Irradiation of barley seeds and its effect on the phytohormonal status of seedlings. Russ. J. Plant Physiol. 2018, 65, 446-454. [CrossRef]

35. Yao, L.; Cheng, X.; Gu, Z.; Huang, W.; Li, S.; Wang, L.; Wang, Y.-F.; Xu, P.; Ma, H.; Ge, X. The AWPM-19 family protein OsPM1 mediates abscisic acid influx and drought response in rice. Plant Cell 2018, 30, 1258-1276. [CrossRef]

36. Mangelsen, E.; Kilian, J.; Harter, K.; Jansson, C.; Wanke, D.; Sundberg, E. Transcriptome analysis of high-temperature stress in developing barley caryopses: Early stress responses and effects on storage compound biosynthesis. Mol. Plant 2011, 4, 97-115. [CrossRef]

37. Barrero, J.M.; Cavanagh, C.; Verbyla, K.L.; Tibbits, J.F.G.; Verbyla, A.P.; Huang, B.E.; Rosewarne, G.M.; Stephen, S.; Wang, P.; Whan, A.; et al. Transcriptomic analysis of wheat near-isogenic lines identifies PM19-A1 and $A 2$ as candidates for a major dormancy QTL. Genome Biol. 2015, 16, 93. [CrossRef]

38. Thor, K. Calcium-Nutrient and Messenger. Front. Plant Sci. 2019, 10. [CrossRef] 
39. Munir, S.; Khan, M.; Song, J.; Munir, S.; Zhang, Y.; Ye, Z.; Wang, T. Genome-wide identification, characterization and expression analysis of calmodulin-like (CML) proteins in tomato (Solanum lycopersicum). Plant Physiol. Biochem. 2016, 102, 167-179. [CrossRef]

40. Bender, K.W.; Rosenbaum, D.M.; Vanderbeld, B.; Ubaid, M.; Snedden, W.A. The Arabidopsis calmodulin-like protein, CML39, functions during early seedling establishment. Plant J. 2013, 76, 634-647. [CrossRef]

41. Midhat, U.; Ting, M.K.Y.; Teresinski, H.J.; Snedden, W.A. The calmodulin-like protein, CML39, is involved in regulating seed development, germination, and fruit development in Arabidopsis. Plant Mol. Biol. 2018, 96, 375-392. [CrossRef] [PubMed]

42. Ma, Q.; Zhou, Q.; Chen, C.; Cui, Q.; Zhao, Y.; Wang, K.; Arkorful, E.; Chen, X.; Sun, K.; Li, X. Isolation and expression analysis of CsCML genes in response to abiotic stresses in the tea plant (Camellia sinensis). Sci. Rep. 2019, 9, 1-9. [CrossRef] [PubMed]

Publisher's Note: MDPI stays neutral with regard to jurisdictional claims in published maps and institutional affiliations.

(C) 2020 by the authors. Licensee MDPI, Basel, Switzerland. This article is an open access article distributed under the terms and conditions of the Creative Commons Attribution (CC BY) license (http://creativecommons.org/licenses/by/4.0/). 